\title{
ASSESSING HABITAT SUITABILITY FOR THE COMMON POCHARD, Aythy a ferina (ANSERIFORMES, ANATIDAE) AT DIFFERENT SPATIAL SCALES IN OREL' RIVER VALLEY, UKRAINE
}

\author{
OLEXANDER PONOMARENKO ${ }^{1}$, MYHAYLO BANIK ${ }^{2}$, OLEXANDER ZHUKOV $凶^{3}$
}

${ }^{1}$ Department of Zoology and Ecology, Oles Honchar Dnipro National University, Gagarin ave., 72, 49010, Dnipro, Ukraine; e-mail: aponomar@ua.fm ${ }^{2}$ Department of Zoology \& Animal Ecology, V.N. Karazin Kharkiv National University, Maidan Svobody 4, 61022, Kharkiv, Ukraine; e-mail: mbanik@operamail.com ${ }^{3}$ Bogdan Khmelnitsky Melitopol State Pedagogical University, Hetmanska st., 20, 72318, Melitopol, Ukraine; e-mail: zhukov_dnipro@ukr.net

$\triangle$ Corresponding author

Received: 13 March 2020 / Accepted: 18 September 2020

\begin{abstract}
Ponomarenko O.L., Banik M.V., Zhukov O.V.: Assessing habitat suitability for the Common Pochard, Aythya ferina (Anseriformes, Anatidae) at different spatial scales in Orel' River valley, Ukraine. Ekológia (Bratislava), Vol. 40, No. 2, p. 154-162, 2021.

The habitat suitability for the Common Pochard, a duck species in decline, was studied in the middle reaches of the Orel' River, Central Ukraine, in 2015-2017. The ducks were counted on their breeding grounds with the use of the ground survey technique. The positions of individual birds were estimated by GPS and plotted on the Google Earth map. The Ecological Niche Factor Analysis (ENFA) was applied to assess the habitat suitability. Sentinel-2 image was used to extract 13 ecogeographical variables and to get two measures of the ecological niche (marginality and specialization). The ENFA procedure was applied twice at landscape and sub-landscape levels to describe the habitat selection across sequential spatial scales. Both the axes of marginality and specialization of the ecological niche of the species proved to be significantly different from the random alternatives. At landscape level, the distribution may be predicted with the use of Aerosol/Coastal, Vegetation and Hydrothermal Composite indices (marginality) and Modified Normalized Difference Water (MNDW) Index along with several vegetation indices (specialization). At sub-landscape level, MNDW played a crucial role. The importance of MNDW is mediated by the preference for the wetlands with the stretches of open water which are used by the ducks to initiate flight safely and to optimize diving possibilities. The ENFA is a reliable tool for the assessment of the habitat suitability and for setting the conservation priorities for the Common Pochard.
\end{abstract}

Key words: Common Pochard, habitat suitability, ecological niche factor analysis, conservation management, Ukraine.

\section{Introduction}

The assessment of habitat suitability is a key issue in speciesoriented conservation management (Larson et al., 2004; Fischer, Lindenmayer, 2007; Kaminski, Elmberg, 2014; Tellería, 2016). Meanwhile such an assessment is hampered by the fact that the animals choose habitats at a hierarchy of spatial dimensions (Tellería, 2016; Elafri et al., 2017) that matches the overall occurrence of ecological structures and processes across multiple spatiotemporal scales (Nash et al., 2014). That is why it's important to look for the habitat suitability at sequential spatial scales especially when considering duck species which often consistently use a suite of wetlands or wetland sections to breed, moult and replenish energetic resources on migration (Kaminski, Elmberg, 2014; Bhattarai, 2019).

Among other Western Palearctic Aythya ducks, the Common Pochard, Aythya ferina (Linnaeus, 1758) (hereafter the Pochard), seems to use a wider range of habitats (Kear, 2005; Petkov, 2012). The species breeds at various natural water bodies from oligotrophic lakes in forest zone to eutrophic lakes in steppes and equally readily on artificial fish ponds within the European portion of the range (Fox, Stawarczyk, 1997). But despite the wide range of habitat tolerance, the Pochard demonstrated clearly negative trends throughout significant parts of its range in recent decades, and since 2015, the species was classified as globally vulnerable (BirdLife International, 2017). The causes of decline are not clear but probably are diverse and may vary in different parts of Europe (Fox et al., 2016).

In 1980s to 1990s, the Pochard was one of the commonest duck species in Ukraine as a whole and in Dnipro region, Central Ukraine, especially, but later on the species has experienced significant decline (Bulakhov et al., 2008; Fox et al., 2016). The unfavourable status of the Pochard urges to collect more detailed data on its breeding distribution and on dependence of the latter on certain environmental factors. The assessment of the availability of water bodies which are suitable for Pochard is crucial because it probably limits the numbers of the species within the region (Bulakhov et al., 2008).

One of the strongholds of the Pochard in Dnipro region specifically and in Central Ukraine in general is the Orel' River val- 
ley, which retained its value for the species to recent times (Fox et al., 2016). The valley was transformed in 1970s and early 1980s through development projects but still is rich in lakes of various sizes, oxbows and small to large wetlands. The great portion of the valley (about 200 thousands hectares) is planned to be protected within the proposed Orilskyi national park (Baranovsky et al., 2013). These plans need to be substantiated in assigning the protection status for certain parts of the territory which in turn should be based on the assessment of the importance of the habitats for vulnerable species. Thus, our studies are in line with the realization of the specific protection measures for the territory of the prospective Orilskyi national park.

The aim of this work is to assess the suitability of the habitats in the middle reaches of the Orel' River, Central Ukraine, for breeding Pochards and to identify the predictors of the distribution of the species through a range of wetland habitats in Ukrainian steppe zone.

\section{Material and methods}

The Orel' River is one of the largest left-bank tributaries of the Dnipro River. Its total length is $346 \mathrm{~km}$. The basin area is $9810 \mathrm{sq}$. $\mathrm{km}$. The basin itself is situated in Prydniprovya lowland within northern portions of the steppe zone in Ukraine. There are 47 small rivers longer than $10 \mathrm{~km}$ (total length $1587 \mathrm{~km}$ ) and 448 small rivers shorter than $10 \mathrm{~km}$ (total length $941 \mathrm{~km}$ ) within the basin. The density of river network is $0.26 \mathrm{~km} / \mathrm{sq}$. $\mathrm{km}$. The width of the Orel' River valley changes from 2 to $3 \mathrm{~km}$ in upper reaches to $16-22 \mathrm{~km}$ in lower reaches. The asymmetry of the valley is apparent through steep right banks and gentle left banks. The valley is well-terraced. There is a plenty of oxbows and lakes and wetlands in Orel' River floodplain. Very peculiar lake-like expanses of the channel are scattered across the middle reaches of the river (Banik et al., 2013; Manyuk, Manyuk, 2016).

The hydrological regime and relief of floodplain terrace of the Orel' River were dramatically transformed when a mighty
Dnipro-Donbass canal was constructed in 1969-1982. The channel of the canal traverses floodplain terrace along with a network of branch canals. The levees were constructed along the channel as well as water pumping stations and inverted tunnels. The banks were framed by planted tree and shrubby vegetation. The canal was constructed for water-carrying capacity of 120-125 $\mathrm{m}^{3} / \mathrm{s}$ (Abroskin, 1975), but from the start date, it never have been used by more than one third of its capacity and often even much lower (e.g. 5.5-10 m³ $/ \mathrm{s}$ in 1998-2000 years; Ekhnych, Kress, 2006). The semi-natural landscapes dominate in the Orel' River basin nowadays. The study area is between Chernetchyna and Pereshchepyne settlements within middle reaches of the Orel' River in Dnipro region, Ukraine (Fig. 1).

The field expedition trips were accomplished in May to July in 2015-2017. As all major water bodies within the study area were concentrated in several portions of the Orel' River valley, they were chosen as census polygons to carry out the surveys. The waterfowl censuses were made using the ground survey technique at early morning or evening hours (Dzubin, 1969; Resources Inventory Committee, 1999). The total of 68 waterfowl and waterbird species was recorded within the study period. The total of 5542 of single registrations of waterfowl and waterbird individuals of which 214 were those of the Pochard was made. The total area that was surveyed comprised 938 ha within polygon no. 1 (66 registrations of single birds or groups), 2851 ha within polygon no. 2 (19 registrations), 11,321 ha within polygon no. 3 (84 registrations) and 3537 ha within polygon no. 4 (45 registrations). The spatial position of individual birds was estimated by means of GPS navigator Garmin e-trex. This was done at first by the fixation of geographical position of the observers and then by determining the azimuthal direction to the location of individual bird or bird groups from several observation points. The location of the birds or bird group was finally plotted on printed satellite images of certain lakes or other water bodies by triangulation method. Additionally, we have used certain landmarks (e.g. free standing reed clumps, promontories and arms and so

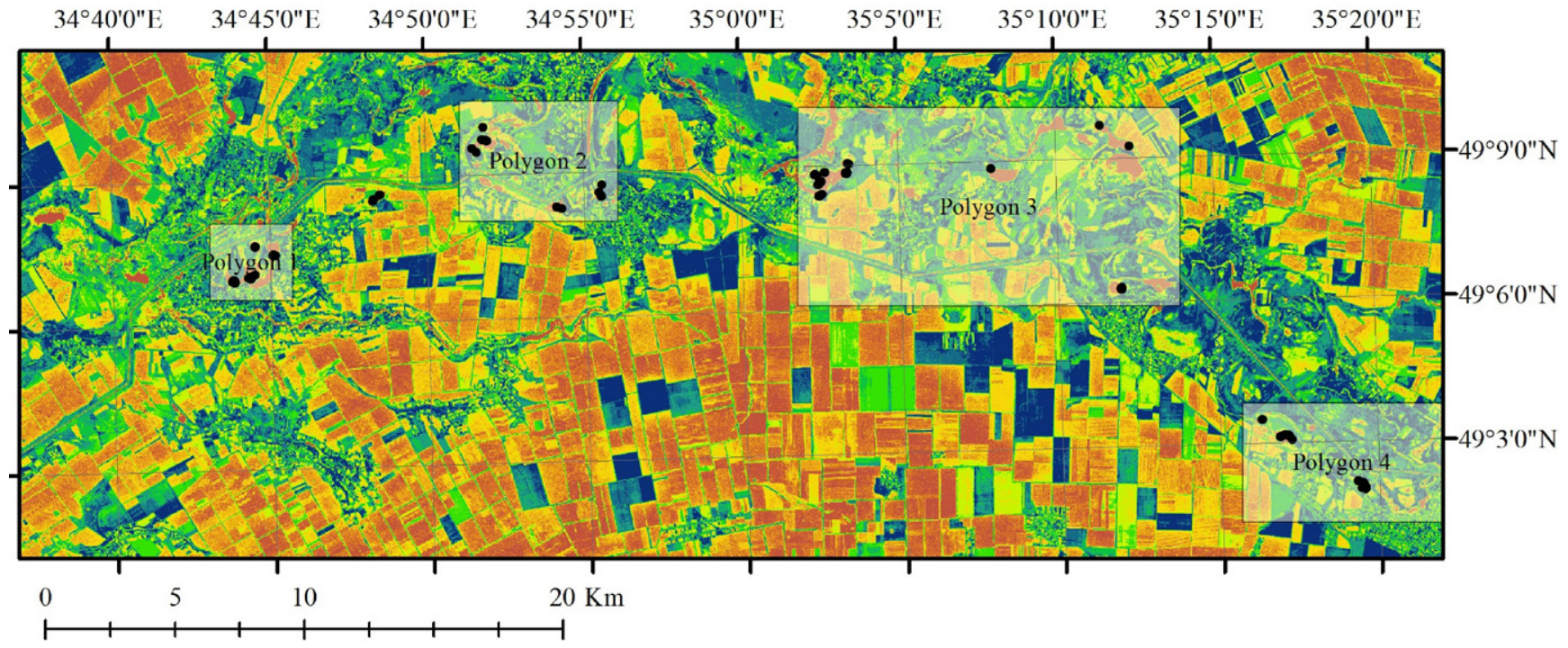

Fig. 1. The location of the sample polygons and the distribution of the points of the Pochard's registrations (dots). Spatial variation of NDVI values based on the results of remote sensing of the Earth's surface by satellite Sentinel-2. 
on) to make more accurate estimates of the location of the birds. The location points were then plotted in Google Earth and exported into text format in the laboratory.

We have used the Ecological Niche Factor Analysis (hereafter the ENFA) to assess the habitat suitability for the Pochard within the study area (Hirzel et al., 2001; Zimaroeva et al., 2016). The ENFA is based on the comparison of the environmental characteristics of the points where the species was occurred with the characteristics of the whole study area (Hirzel et al., 2002; Yorkina et al., 2018). These characteristics are called ecogeographical variables (thereafter EGV) (Hirzel et al., 2002). The essence of the ENFA is in comparison of the distribution of the species regarding EGV with the overall distribution of EGV within the study area. The measure which accounts for the differences in the mean of the two distributions is called marginality, while another measure called specialization deals with the differences in the variance (Hirzel et al., 2002). The latter is indeed a set of factors consecutively extracted when relating the variance of the overall distribution of EGV to the variance of the species distribution. Marginality and specialization are quite useful to define the habitat suitability for a given species (Hirzel et al., 2001). Graphical representation is one convenient way to demonstrate the significance of both marginality and specialization. The results of the applied statistical procedures are often used to produce maps showing the zones of the likelihood of the occurrence of the species.

The sensitivity of the ENFA procedure to the reference area was already stressed by the authors of the method (Hirzel et al., 2002). We have used this to get more comprehensive view of the habitat preferences of the Pochard. We have applied the ENFA procedure twice, at whole-plot level for the study area as a whole and at sub-plot level within four designated sample polygons. This strategy of changing the scale of the reference area for the ENFA procedure corresponds to the implications from B.E. Hutchinson's concept of ecological niche (Hutchinson, 1957, 1965). Each such change can be considered as an attempt to estimate realized versus fundamental niche at sequential spatial scales that reflect the habitat choice at landscape and sublandscape levels. When detecting habitat suitability at landscape level, we try to understand what is distinct in used landscape elements as compared to non-utilized. At subordinate levels, we can catch preferred habitat characteristics or even micro-habitat choice in heterogeneous habitats (Ponomarenko, 2017). This approach was successfully used to analyse habitat preferences of the Great Tit, Parus major Linnaeus, 1758 (Zimaroeva et al., 2016), and the Mute Swan, Cygnus olor (Gmelin, 1789) (Andrushenko, Zhukov, 2016).

A satellite image taken by Sentinel-2 (2017/05/17, ID: L1C T36UXV_A009928_20170517T084016) was used to extract EGV for the purpose of this study (for spectral band characteristics, see Drusch et al., 2012; Sentinel-2, 2012). The following environmental indices (ratio of spectral bands B1-B12) were derived from the satellite image and applied in the ENFA:

Aerosol/Coastal Index $(\mathrm{AC}-$ Index $=(\mathrm{B} 1-\mathrm{B} 2) /(\mathrm{B} 1+\mathrm{B} 2))$ characterizes the concentration of aerosols in the atmosphere and may also help to tell apart areas of shallow waters within coastal zone or in inland water bodies (Yale Center for Earth Observation, 2019).

Hydrothermal Composite (or Mineral Composite, or Iron Oxide Composite) ( $\mathrm{HC}=\mathrm{B} 4 / \mathrm{B} 2)$ allows to differentiate water objects from soils and is sensitive to the iron compounds' content of the upper soil layers (ERDAS Field Guide, 2002).

Vegetation Index $(\mathrm{VI}=(\mathrm{B} 11-\mathrm{B} 12) /(\mathrm{B} 11+\mathrm{B} 12))$ is sensitive to non-photosynthetic vegetation (vegetation types) and soil cover (van Deventer et al., 1997; Jensen, 2005; Dai et al., 2018).

Normalized Difference Vegetation Index $($ NDVI $=(B 8-$ $\mathrm{B} 4) /(\mathrm{B} 8+\mathrm{B} 4))$ accounts for primary production and transpiration rate (Jensen, 2005; Clerici et al., 2017; Ranjbar et al., 2018). Green Normalized Difference Vegetation Index (GreenNDVI = $(\mathrm{B} 7-\mathrm{B} 3) /(\mathrm{B} 7+\mathrm{B} 3))$ is the vegetation index which is sensitive to the chlorophyll content in vegetation (Gitelson et al., 1996; Navarro et al., 2017). Red Edge Chlorophyll Index $\left(\mathrm{CI}_{\text {RedEdge }}=\right.$ $(\mathrm{B} 7-\mathrm{B} 5) /(\mathrm{B} 7+\mathrm{B} 5))$ is an index of the chlorophyll content in vegetation; it can be used also to differentiate burnt areas (Sims, Gamon, 2002; Addabbo et al., 2016; Fernández-Manso et al., 2016).

Modified Normalized Difference Water Index (MNDW = $(\mathrm{B} 3-\mathrm{B} 11) /(\mathrm{B} 3+\mathrm{B} 11))$ is an efficient tool for differentiating water objects (Xu, 2006; Du et al., 2016). Xanthophyll Index (XI $=(\mathrm{B} 3-\mathrm{B} 4) /(\mathrm{B} 3+\mathrm{B} 4))$ is the index which is sensitive to the xanthophyll content in vegetation (Sims, Gamon, 2002; Kunah, Papka, 2016). Chlorophyll Index $(\mathrm{Chl}=(\mathrm{B} 8 \mathrm{a} /(\mathrm{B} 3+\mathrm{B} 4))$ is the index which is sensitive to the chlorophyll content in vegetation (Kunah, Papka, 2016). Land Surface Water Index, Normalized Difference Infrared Index $(\mathrm{LSWI}=(\mathrm{B} 8 \mathrm{a}-\mathrm{B} 11) /(\mathrm{B} 8 \mathrm{a}+11))$ is the index which is sensitive to the water content of vegetation and soil surface (Chandrasekar et al., 2010).

Normalized Burn Ratio Index $(\mathrm{NBR}=(\mathrm{B} 8 \mathrm{a}-\mathrm{B} 12) /(\mathrm{B} 8 \mathrm{a}+$ $\mathrm{B} 12)$ ) is sensitive to the state of open soil surfaces and to the severity of burnt areas (Key, Benson, 2006; Escuin et al., 2008; Fernández-Manso et al., 2016). Normalized Difference Moisture Index $(\mathrm{NDMI}=(\mathrm{B} 8 \mathrm{a}-\mathrm{B} 2) /(\mathrm{B} 8 \mathrm{a}+\mathrm{B} 2))$ is sensitive to the water content of the vegetation (Wilson, Sader, 2002; Jin, Sader, 2005). Leaf Area Index $(\mathrm{LAI}=(\mathrm{B} 5-\mathrm{B} 4) /(\mathrm{B} 5+\mathrm{B} 4))$ is the ratio of the area of the leaves to the area of ground surface (Delegido et al., 2011).

The statistical significance of the ENFA model was tested with the use of the Monte Carlo procedure able to generate the alternative distributions randomly. The procedure was applied to generate 99 random distributions of the Pochard within the study area which then were compared to the actual distribution of the species with the use of the function randtest of the library ade4 (Dray, Dufour, 2007).

Statistical calculations were performed by the Statistica 7.0 software and the project for statistical computations R (R Core team, 2015) using adehabitat (Calenge, 2006) and vegan (Oksanen et al., 2017) libraries. Two-dimensional mapping, estimation of geostatistics and creation of asc-files with data of spatial variability of the environment indicators were accomplished with the use of Surfer 8.0 and ArcGis 10.0 software.

\section{Results}

\section{The distribution of the Pochard at landscape level}

The distribution of the Pochard registrations regarding the studied EGV differs from that of the set of cells for the whole studied area (Fig. 2). These differences can be presented in the terms of its means and thus be interpreted as the marginality of the spe- 

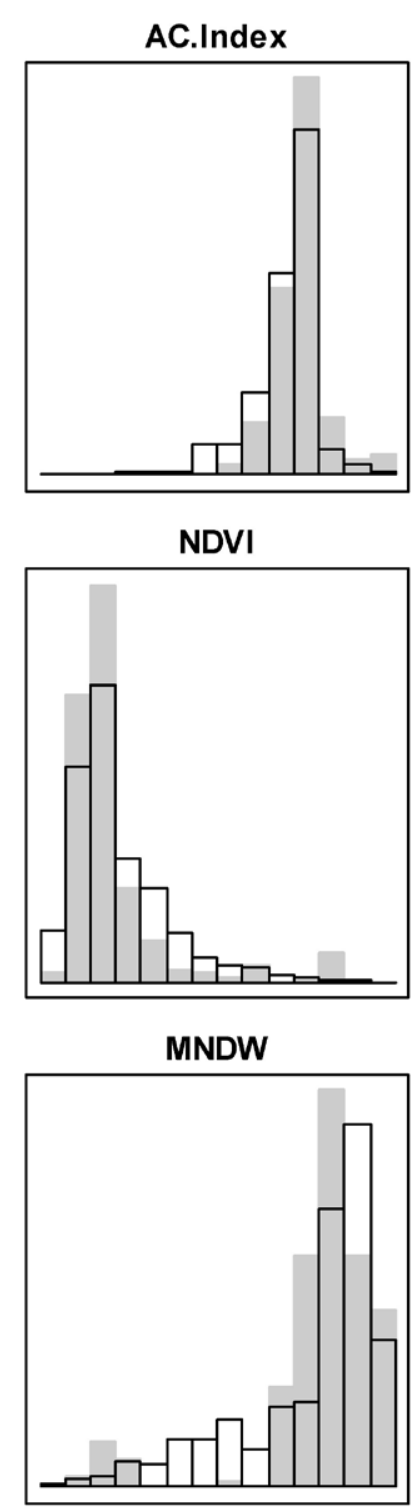

LSWI

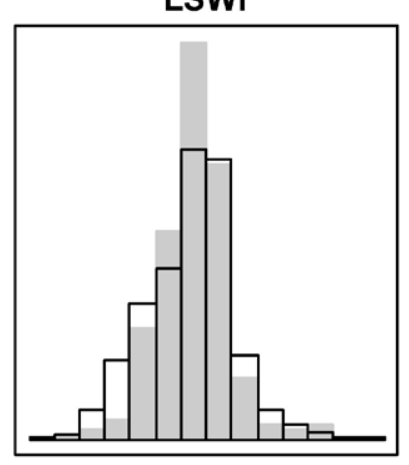

Hydrothermal_Composite
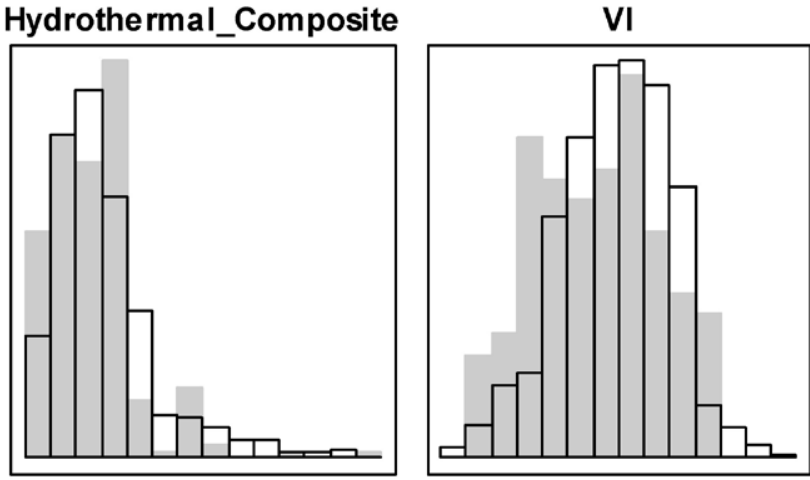

GreenNDVI

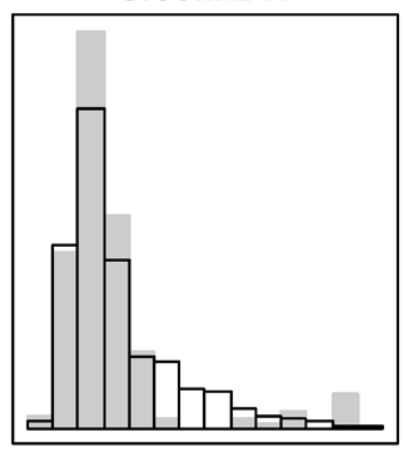

Xanthophyll

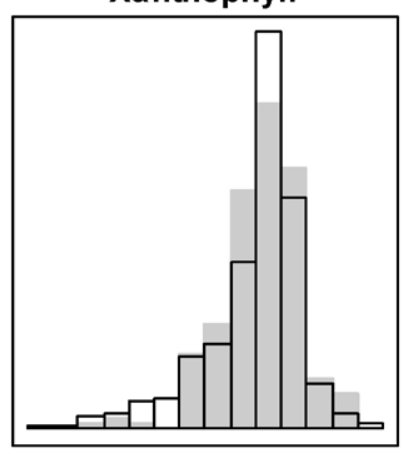

NBR

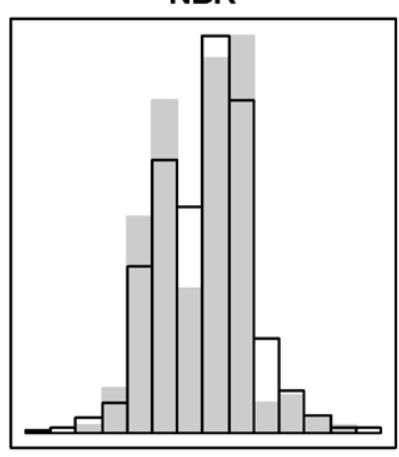

CIRedEdge

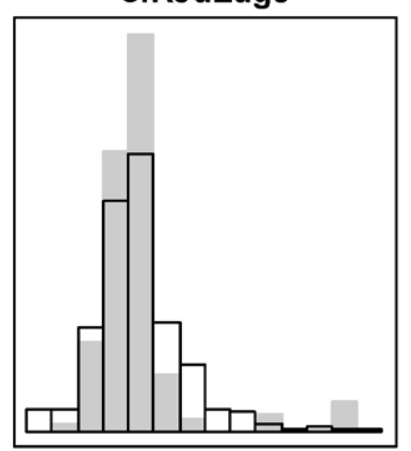

Chlorophyll

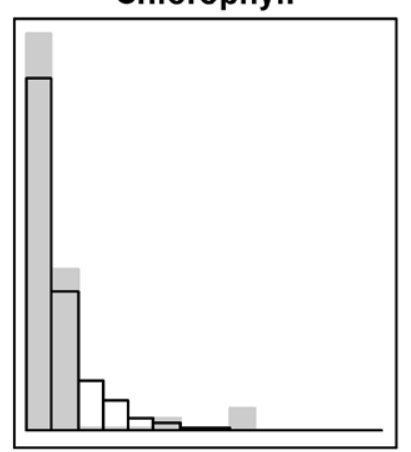

NDMI

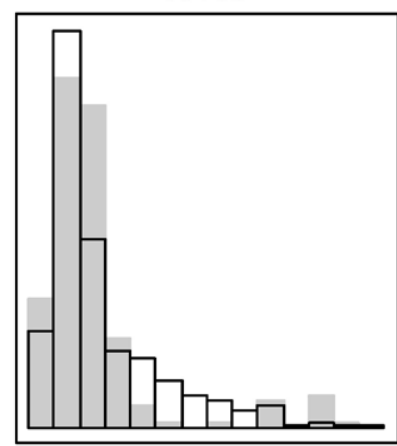

Fig. 2. The histograms of the available resource distribution (white bars) and histograms of the used resource distribution (grey bars) for the Pochard within the study area.

Notes: AC-Index, Aerosol/Coastal Index; Hydrothermal Composite, Hydrothermal Composite Index; VI, Vegetation Index; NDVI, Normalized Difference Vegetation Index; GreenNDVI, Green Normalized Difference Vegetation Index; $\mathrm{CI}_{\text {Rededge }}$ Red Edge Chlorophyll Index; MNDW, Modified Normalized Difference Water Index; Xanthophyll, Xanthophyll Index; Chlorophyll, Chlorophyll Index; LSWI, Land Surface Water Index; NBR, Normalized Burned Ratio Index; NDMI, Normalized Difference Moisture Index. 
Table 1. The correlation of the ecogeographical variables (EGV) and the axes of marginality and specialization of the Pochard at landscape level.

\begin{tabular}{|c|c|c|c|}
\hline Ecogeographical variables & Mar & Spe1 & Spe2 \\
\hline AC-Index (aerosol concentration, water turbidity, shallows) & 0.65 & 0.05 & 0.02 \\
\hline Hydrothermal Composite (water surface, soil) & -0.29 & 0.08 & 0.23 \\
\hline VI (non-photosynthetic vegetation, soil) & -0.47 & -0.02 & 0.03 \\
\hline NDVI (vegetation production) & -0.15 & -0.13 & -0.25 \\
\hline GreenNDVI (chlorophyll content) & -0.18 & -0.53 & -0.03 \\
\hline $\mathrm{CI}_{\text {RedEdge }}$ (chlorophyll content, burnt areas) & -0.01 & 0.42 & 0.20 \\
\hline MNDW (water objects) & 0.19 & -0.59 & -0.54 \\
\hline Xanthophyll (vegetation yellowness) & 0.19 & -0.03 & 0.03 \\
\hline Chlorophyll (chlorophyll content) & -0.06 & -0.33 & 0.03 \\
\hline LSWI (water content of vegetation) & 0.15 & 0.13 & 0.26 \\
\hline NBR (open soil surface, burnt areas) & -0.13 & 0.09 & -0.05 \\
\hline NDMI (water content of vegetation) & -0.20 & 0.04 & -0.66 \\
\hline Leaf Area Index (leaf area) & -0.25 & 0.14 & 0.21 \\
\hline
\end{tabular}

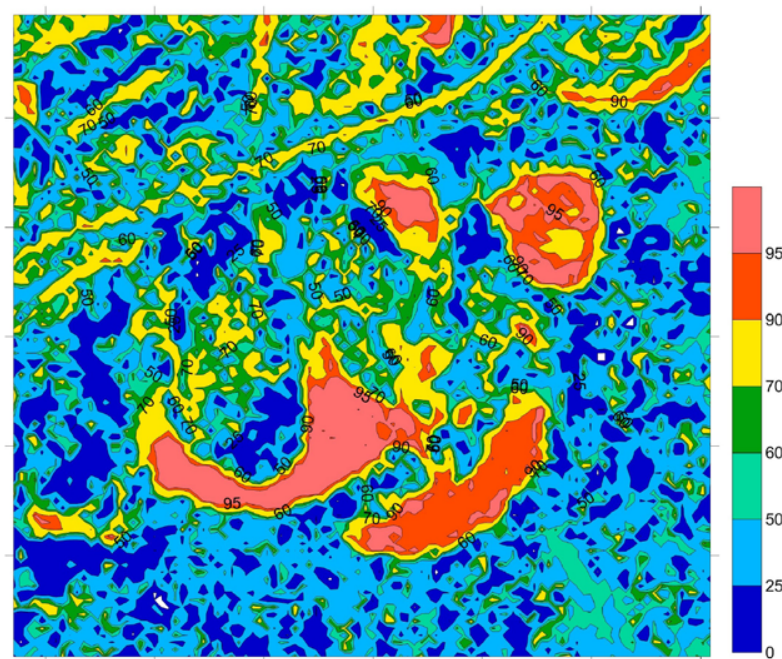

Polygon 1

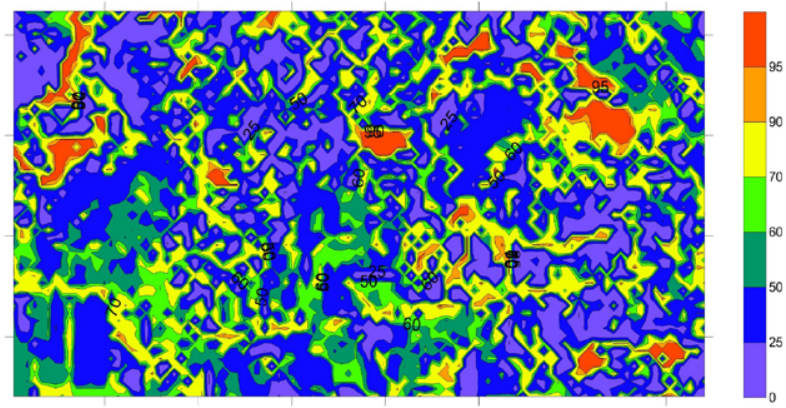

Polygon 3

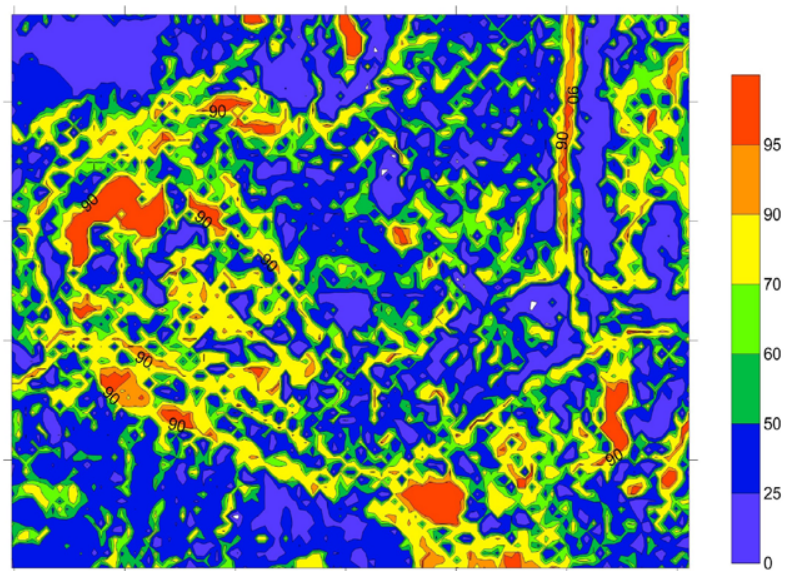

Polygon 2

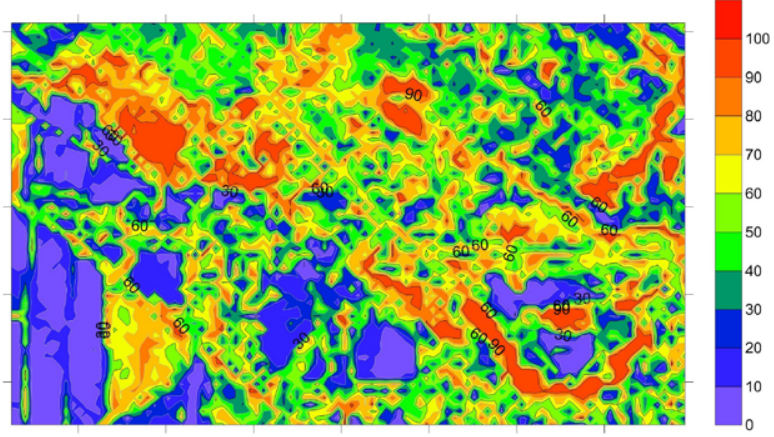

Polygon 4

Fig. 3. The indices of the habitat preference of the Pochard within surveyed polygons. The colour chart of the probability of the occurrence of the Pochard in certain habitat is given beside each image.

cies niche on the corresponding EGV. In turn, the differences between variances reflect the specialization of the ecological niche. Indeed, ecological marginality on the different EGV may be correlated that is why we can extract axes as integral measure of the marginality of the ecological niche. Similar considerations may be applied to the specialization of the species niche. The ENFA approach allows distinguishing the axis of marginality and the axis of specialization. The statistical test proved that an axis of 
Table 2. The correlation of the ecogeographical variables (EGV) and the axes of marginality and specialization of the Pochard at sublandscape level.

\begin{tabular}{|c|c|c|c|c|c|c|c|c|c|c|c|c|}
\hline \multirow{2}{*}{$\begin{array}{l}\text { Ecogeographical } \\
\text { variables }\end{array}$} & \multicolumn{3}{|c|}{ Polygon 1} & \multicolumn{3}{|c|}{ Polygon 2} & \multicolumn{3}{|c|}{ Polygon 3} & \multicolumn{3}{|c|}{ Polygon 4} \\
\hline & Mar & Spe1 & Spe2 & Mar & Spe1 & Spe2 & Mar & Spe1 & Spe2 & Mar & Spe1 & Spe2 \\
\hline AC-Index & 0.21 & 0.00 & 0.00 & 0.21 & 0.00 & 0.00 & 0.26 & 0.00 & 0.00 & 0.26 & 0.02 & 0.00 \\
\hline $\mathrm{HC}$ & -0.30 & 0.02 & 0.03 & -0.30 & -0.03 & 0.00 & -0.28 & -0.03 & 0.00 & -0.24 & -0.05 & 0.01 \\
\hline VI & -0.05 & 0.00 & 0.01 & -0.03 & 0.00 & 0.10 & 0.02 & 0.01 & -0.09 & 0.00 & -0.24 & -0.11 \\
\hline NDVI & -0.31 & 0.80 & -0.47 & -0.28 & -0.82 & -0.72 & -0.25 & -0.80 & 0.77 & -0.27 & -0.09 & 0.37 \\
\hline GreenNDVI & -0.37 & -0.13 & -0.43 & -0.38 & 0.22 & 0.11 & -0.38 & 0.09 & -0.32 & -0.39 & 0.18 & 0.39 \\
\hline $\mathrm{CI}_{\text {RedEdge }}$ & -0.30 & -0.49 & 0.62 & -0.30 & 0.41 & 0.43 & -0.28 & 0.49 & -0.30 & -0.31 & -0.07 & -0.56 \\
\hline MNDW & 0.43 & -0.01 & -0.14 & 0.48 & 0.02 & -0.05 & 0.50 & 0.02 & 0.07 & 0.53 & 0.14 & 0.05 \\
\hline Xanthophyll & 0.20 & -0.03 & -0.11 & 0.19 & 0.08 & 0.05 & 0.21 & 0.02 & -0.15 & 0.11 & 0.04 & 0.22 \\
\hline Chlorophyll & -0.26 & 0.12 & -0.11 & -0.24 & -0.13 & -0.18 & -0.22 & -0.10 & 0.17 & -0.23 & 0.09 & 0.02 \\
\hline LSWI & 0.19 & 0.00 & 0.07 & 0.15 & -0.02 & 0.22 & 0.15 & 0.00 & -0.21 & 0.07 & -0.57 & -0.26 \\
\hline NBR & 0.11 & 0.01 & -0.02 & 0.09 & 0.01 & -0.32 & 0.11 & -0.02 & 0.26 & 0.05 & 0.72 & 0.32 \\
\hline NDMI & -0.38 & -0.06 & -0.09 & -0.40 & 0.08 & 0.00 & -0.40 & 0.06 & 0.00 & -0.42 & 0.13 & 0.07 \\
\hline LAI & -0.25 & -0.30 & 0.38 & -0.20 & 0.29 & 0.30 & -0.16 & 0.32 & -0.20 & -0.14 & -0.06 & -0.41 \\
\hline
\end{tabular}

Notes: AC-Index, Aerosol/Coastal Index; HC, Hydrothermal Composite Index; VI, Vegetation Index; NDVI, Normalized Difference Vegetation Index; GreenNDVI, Green Normalized Difference Vegetation Index; $\mathrm{CI}_{\text {Rededge }}$, Red Edge Chlorophyll Index; MNDW, Modified Normalized Difference Water Index; Xanthophyll, Xanthophyll Index; Chlorophyll, Chlorophyll Index; LSWI, Land Surface Water Index; NBR, Normalized Burned Ratio Index; NDMI, Normalized Difference Moisture Index; LAI, Leaf Area Index.

marginality of the ecological niche of the Pochard $\left(\gamma_{\text {marg }}=0.48\right.$, $p<0.01)$ and two axes of specialization $\left(\gamma_{\text {spec }}=3.90, p<0.03\right.$; $\left.\gamma_{\text {spec } 2}=2.89, p<0.01\right)$ are significantly different from the random alternatives. The ENFA results reveal that the marginality axis is most correlated with Aerosol/Coastal Index, Vegetation Index and Hydrothermal Composite (Table 1). The correlation between specialization axis 1 and EGVs shows the considerable role of the MNDW, GreenNDVI, $\mathrm{CI}_{\text {RedEdge }}$ and Chlorophyll indexes in shaping the specialization aspect of the ecological niche of the Pochard (Table 1). The specialization axis 2 is most correlated with NDMI and MNDW index (Table 1).

\section{The distribution of the Pochard at sub-landscape level}

The records of the Pochard within the study area were concentrated within four polygons (Fig. 3). The ENFA procedure was applied within the polygons to get clearer picture of the habitat preferences of the Pochard. The data on marginality and specialization coefficients for the sub-landscape round of the ENFA application are given in Table 2. At sub-landscape level, the marginality is represented by EGV which are mainly linked to vegetation characteristics such as NDVI, GreenNDVI and NDMI but also to water objects, e.g. MNDW and Hydrothermal Composite (Table 2). The vegetation indices (NDVI, $\mathrm{CI}_{\text {RedEdge }}$ LAI and others) demonstrated also considerable role at both axes of specialization though not consistent for every polygon (Table 2).

\section{Discussion}

The highest correlation coefficient among EGV at the marginality axis at landscape level was for the AC-Index. As the study area is far apart from coastal regions where the index can point mainly to the water turbidity and shallows, it's reasonable to account for its strong correspondence to the aerosol and dust content in the atmosphere preferentially. The scattering by dust particles increases the reflectance in the red channel concurrently decreasing the vegetation indices (Gitelson et al., 1996). In other words, the effects at aerosol-coastal band are most probably a reflection of the link between the distribution of the Pochard in relation to the vegetation production (see also the inverse signs of the coefficients for the AC-Index and vegetation indices; Tables 1 and 2).

$\mathrm{VI}$ is the second most important among EGV at marginality axis. The distribution of the Pochard is inversely related to the extent of non-photosynthetic vegetation that in this case can be possibly the dead reed stems at wetland complexes. But this explanation remains dubious as there is no indication of the links between this index and the Pochard distribution at sublandscape level.

Hydrothermal Composite is the third most important factor for the distribution of the Pochard at landscape level. This index which is sensible to yellow parts of the spectrum is used most often to indicate the high content of clay or to indicate bare sites. But it also is useful to tell water objects from soil surfaces, to estimate the moisture content and prospective yield in crops. We consider the relation of this index to the distribution of the Pochard as merely an indication of the preference for the water bodies.

Specialization coefficients correspond to the breadth of the habitat preferences of the species (Francesiaz et al., 2017). MNDW was the most important among EGV for specialization 1 axis at landscape level. This index is a powerful tool for discriminating open water areas from other types of surface, e.g. built-up areas, bare soils and areas covered by vegetation of any kind $(\mathrm{Xu}$, 2006). The role of this index for the distribution of the Pochard is detailed below.

NDMI proved to be the most important factor in the distribution of the Pochard by specialization 2 axis at landscape level. NDMI points to the water content in vegetation (but also 
to the changes in vegetation biomass; see Wilson, Sader, 2002) and can be considered within a group of other vegetation indices which proved to be significant in shaping specialization axis 1 (GreenNDVI, $\mathrm{CI}_{\text {RedEdge }}$, Chlorophyll). The distribution of the Pochard is shifted to the areas where the values of these indices are lower or in other words where there are less dense and less developed vegetation of any kind.

The results of the application of the ENFA show that AC-Index, VI and Hydrothermal Composite may be used to find and delineate the territories which are suitable for the Pochard at landscape level.

The highest marginality coefficient at sub-landscape level was for the Modified Normalized Difference Water (MNDW) Index. This EGV dominated as main marginality parameter at every of four studied polygons proving the significance of the results. The MNDW Index itself as was already mentioned is a very powerful tool in telling open water surfaces from other surface types including urbanized lands and built-up territories and more importantly wetlands overgrown by vegetation $(\mathrm{Xu}$, 2006). At sub-landscape level within our study area where there are no great artificial water reservoirs, MNDW Index most probably indicates the presence of the stretches of open water within wetland complexes with considerable areas covered by emergent vegetation, e.g. cattail and reed stands.

The significance of MNDW Index in shaping habitat suitability profile for the Pochard is most likely in optimal for the species balance between stretches of open, comparatively deep waters and shallow sites with high vegetation production. In general, diving ducks demonstrate a trade-off between adaptations to diving and flying abilities (Bethke, Thomas, 1988). The Pochard was reported to be more prone to open and deeper waters as e.g. Red-crested Pochard, Netta rufina (Pallas, 1773) (Amat, 1984). The Pochards need bigger distances when running over open water to take flight comparing to other Palearctic Aythya ducks (Hori, 1966; Cramp, 1977). There may be a strong preference in the Pochard for water bodies with reasonable areas of open surface which are necessary and sufficient for these ducks to initiate flight safely and to meet optimal possibilities for diving.

MNDW Index may be an effective instrument for delineation of the habitats which are highly suitable for the Pochard while its dynamics may have an effect on the occurrence of the Pochard and its density.

Three more comparatively high coefficients on marginality axis were those for NDMI, GreenNDVI and $\mathrm{CI}_{\text {RedEdge }}$ indices, while the most significant EGV on specialization axes (Spe1, Spe2) at polygons 1-3 was the Normalized Difference Vegetation Index (NDVI), which points to the vegetation primary production. $\mathrm{CI}_{\text {RedEdge }}$ index apart of NDVI was the most significant at both specialization axes 1 and 2, while correlation coefficients for GreenNDVI and LAI indices were comparatively high at specialization axis 2 . All these vegetation indices can be considered together as additional clues for the characterization of the habitats of the Pochard, but no special causal links are indeed apparent apart from the trivial relation to the areas where the density and biomass of the vegetation is lower.

Comparatively high correlation coefficients for AC-Index and Hydrothermal Composite at marginality axis at sub-landscape level are quite similar to the results for the landscape level and indicate both possible interrelations of AC-Index with vegetation indices and the natural dependence of the Pochard on water bodies and wetlands (see above).
The essential aspects of the Pochard distribution are discernable on satellite images (Figs 1 and 3). The Pochard occurs on lake systems but not on desolate water bodies within the study area. The water bodies which are most suitable for the Pochard are clustered as can be seen on all images (Fig. 3). This is in line with the known habitat requirements of the Redhead, $A y$ thya americana (Eyton, 1838), the Pochard's Nearctic counterpart, which uses smaller wetlands in surroundings of the bigger lakes as optimal breeding sites (Custer, 1993). However, for the Pochard in Central Ukraine, this is only a preliminary observation to be demonstrated at larger spatial scale.

All four polygons represent the systems of oxbows and lakelike expanses of the Orel' River channel which are largely degraded nowadays. Initially, such lakes were bigger and much of the current fragments were connected in all-in-one branchy water body. The fragmentation probably has begun after the construction of the Dnipro-Donbass canal and is now apparent at every studied polygon, especially polygons 2 and 3 . The main causes of the fragmentation are the disturbance of hydrological regime due to the canal construction and the absence of seasonal spring floods in the last two decades. The processes of overgrowing and eutrophication paralleled the fragmentation. Probably, all these processes resulted in critical reduction of the areas at water bodies which are suitable for the Pochard.

\section{Conclusion}

The results of this study clearly show that the ENFA is an effective tool for the detection and assessment of the habitats which are suitable for breeding Pochards. The ENFA procedure enabled not only to estimate the habitat suitability but also to detect the areas which are prospectively important for the Pochard. The results demonstrated also that the Pochard is not an over-generalistic species in its use of the habitats but prefers the water bodies of certain nature.

The Orel' River valley, Central Ukraine, possesses the areas with suitable habitats which are sufficiently large to maintain viable population of the species. The habitat requirements of the Pochard proved to be distinct at landscape level (the whole study area) and at sub-landscape level (polygons). Most probably, the Pochard relies on the presence of the stretches of open water within wetland complexes. The tendency to breed on complexes or groups of lakes and avoidance of desolate water bodies should be better substantiated in the future.

\section{Acknowledgements}

We are very grateful to all those people who provide invaluable help and support at all stages of our field work, namely Andrey Atemasov, Roman Barabash, Hennadiy Goncharov, Olexiy Korshunov and Eugene Skorobogatov.

\section{References}

Abroskin, G.I. (1975). Dnepr-Donbass canal. Hydrotechnical Construction, 9(11), 1027-1029. DOI: 10.1007/BF02382348.

Addabbo, P., Focareta, M., Marcuccio, S., Votto, C. \& Ullo S.L. (2016). Contribution of Sentinel-2 data for applications in vegetation monitoring Acta IMEKO, 5(2), 44-54. DOI: 10.21014/acta_imeko.v5i2.352.

Amat, J.A. (1984). Ecological segregation between Red-crested Pochard Netta rufina and Pochard Aythya ferina in a fluctuating environment. Ardea, 72, 229-233. 
Andrushenko, A.Yu. \& Zhukov A.V. (2016). Scale-dependent effects in structure of the wintering ecological niche of the Mute Swan during wintering in the Gulf of Sivash (in Russian). Biological Bulletin of Bogdan Khmelnitskiy Melitopol State Pedagogical University, 6(3), 234-247. DOI: $10.15421 / 201691$.

Banik, M.V., Atemasov, A.A., Goncharov, G.L., Saidakhmedova, N.B., Nadtochiy, G.S. \& Biatov A.P. (2013). Key wetlands in Kharkiv region: current state and compliance with Ramsar Convention (in Ukrainian). Nature Reserve in Ukraine, 19(1), 1-5.

Baranovsky, B.O., Manyuk, V.V., Demyanov, V.V., Chegorka, P.T. \& Hrytsan Y.I. (2013). The current state of the environment in the Orel' River basin in the scope of the creation of national nature park 'Orilskyi' (in Ukrainian). Bulletin Dnipro State Agrarian University, 32(2), 55-60.

Bethke, R.W. \& Thomas V.G. (1988). Differences in flight and heart muscle mass among geese, dabbling ducks, and diving ducks relative to habitat use. Can. J. Zool., 66, 2024-2028. DOI: 10.1139/z88-297.

Bhattarai, B.P. (2019). Factors associated with habitat segregation among the four species of cervids in the Chitwan National Park, Nepal. Ekológia (Bratislava), 38(1), 37-48. DOI: 10.2478/eko-2019-0004.

BirdLife International (2017). Aythya ferina (amended version of 2016 assessment). The IUCN Red List of Threatened Species 2017: e.T22680358A110610804. DOI: 10.2305/IUCN.UK.2017-1.RLTS T22680358A110610804.en.

Bulakhov, V.L., Gubkin, A.A., Ponomarenko, O.L. \& Pakhomov O.Ye. (2008). Biological diversity of Ukraine. Dnipropetrovsk region. Birds: Non-passerines (Aves: Non-Passeriformes) (in Ukrainian). Dnipropetrovsk: Dnipropetrovsk National University.

Calenge, C. (2006). The package "adehabitat" for the R software: A tool for the analysis of space and habitat use by animals. Ecol. Model., 197, 516-519. DOI: 10.1016/j.ecolmodel.2006.03.017.

Chandrasekar, K., Sesha Sai, M.V.R., Roy, P.S. \& Dwevedi R.S. (2010). Land Surface Water Index (LSWI) response to rainfall and NDVI using the MODIS Vegetation Index product. Int. J. Remote Sens., 31(15), 39874005. DOI: $10.1080 / 01431160802575653$.

Clerici, N., Calderón, C.A.V. \& Posada J.M. (2017). Fusion of Sentinel-1A and Sentinel-2A data for land cover mapping: a case study in the lower Magdalena region, Colombia. Journal of Maps, 13(2), 718-726. DOI: 10.1080/17445647.2017.1372316.

Cramp, S. (Ed.) (1977). Handbook of the Birds of Europe, the Middle East and North Africa. The Birds of the Western Palearctic. Vol. 1: Ostrich to Ducks. Oxford: Oxford University Press.

Custer, C.M. (1993). Life History Traits and Habitat Needs of the Redhead. In D.H. Cross \& P. Vohs (Eds.), Waterfowl Management Handbook (pp. 1-7). Fort Collins: US Fish \& Wildlife Service.

Dai, J., Roberts, D., Dennison, P. \& Stow D. (2018). Spectral-radiometric differentiation of non-photosynthetic vegetation and soil within Landsat and Sentinel 2 wavebands. Remote Sensing Letters, 9(8), 733-742. DOI: 10.1080/2150704X.2018.1470697.

Delegido, J., Verrelst, J., Alonso, L. \& Moreno J. (2011). Evaluation of Sentinel-2 red edge bands for empirical estimation of green LAI and chlorophyll content. Sensors, 11(7), 7063-7081. DOI: 10.3390/s110707063.

Dray, S. \& Dufour A.-B. (2007). The ade4 Package: Implementing the Duality Diagram for Ecologists. Journal of Statistical Software, 22(4), 1-20. DOI 10.18637/jss.v022.i04.

Drusch, M., Del Bello, U., Carlier, S., Colin, O., Fernandez, V., Gascon, F., Hoersch, B., Isola, C., Laberinti, P., Martimort, P., Meygret, A., Spoto, F., Sy, O., Marchese, F. \& Bargellini P. (2012). Sentinel-2: ESA's Optical High-Resolution Mission for GMES Operational Services. Remote Sens. Environ., 120, 25-36. DOI: 10.1016/j.rse.2011.11.026.

Du, Y., Zhang, Y., Ling, F., Wang, Q., Li, W. \& Li X. (2016). Water Bodies' Mapping from Sentinel-2 Imagery with Modified Normalized Difference Water Index at 10-m Spatial Resolution Produced by Sharpening the SWIR Band. Remote Sensing, 8, 354. DOI: 10.3390/rs8040354.

Dzubin, A. (1969). Assessing breeding populations of ducks by ground counts. Saskatoon Wetlands Seminar. Canadian Wildlife Service Report Series, 6, 178-237.

Ekhnych, M.P. \& Kress L.E. (2006). River hydrography (in Ukrainian). Dnipropetrovsk: PBP Ekonomyka.

Elafri, A., Belhamra, M. \& Houhamdi M. (2017). Comparing habitat preferences of a set of waterbird species wintering in coastal wetlands of North Africa: implication for management. Ekológia (Bratislava), 36(2), 158171. DOI: 10.1515 /eko-2017-0014
ERDAS Field Guide (2002). Atlanta: ERDAS LLC.

Escuin, S., Navarro, R. \& Fernández P. (2008). Fire severity assessment by using NBR (Normalized Burn Ratio) and NDVI (Normalized Difference Vegetation Index) derived from LANDSAT TM/ETM images. Int. J. Remote Sens., 29(4), 1053-1073. DOI: 10.1080/01431160701281072.

Fernández-Manso, A., Fernández-Manso, O. \& Quintano C. (2016). SENTINEL-2A red-edge spectral indices suitability for discriminating burn severity. International Journal of Applied Earth Observation Geoinformation, 50, 170-175. DOI: 10.1016/j.jag.2016.03.005.

Fischer, J. \& Lindenmayer D.B. (2007). Landscape modification and habitat fragmentation: a synthesis. Glob. Ecol. Biogeogr., 16, 265-280. DOI 10.1111/j.1466-8238.2007.00287.x.

Fox, A.D., Caizergues, A., Banik, M.V., Devos, K., Dvorak, M., Ellermaa, M., Folliot, B., Green, A.J., Grüneberg, C., Guillemain, M., Håland, A., Hornman, M., Keller, V., Koshelev, A.I., Kostiushyn, V.A., Kozulin, A., Ławicki, Ł., Luigujõe, L., Müller, C., Musil, P., Musilová Z., Nilsson, L., Mischenko, A., Pöysä, H., Ščiban, M., Sjeničić, J., Stīpniece, A., Švažas, S. \& Wahl J. (2016). Recent changes in the abundance of Common Pochard Aythya ferina breeding in Europe. Wildfowl, 66, 22-40.

Fox, T. \& Stawarczyk T. (1997). Pochard Aythya ferina. In E.J.M. Hagemeijer \& M.J. Blair (Eds.), The EBCC Atlas of European Breeding Birds: Their distribution and abundance (pp. 102-103). London: T \& A D Poyser.

Francesiaz, C., Guilbault, E., Lebreton, J.-D., Trouvilliez, J. \& Besnard A. (2017). Colony persistence in waterbirds is constrained by pond quality and land use. Freshw. Biol., 62(1), 119-132. DOI: 10.1111/fwb.12855.

Gitelson, A.A., Kaufman, Y.J. \& Merzlyak M.N. (1996). Use of a green channel in remote sensing of global vegetation from EOS-MODIS. Remote Sens. Environ., 58, 289-298. DOI: 10.1016/S0034-4257(96)00072-7.

Hirzel, A.H., Hausser, J., Chessel, D. \& Perrin N. (2002). Ecological-niche factor analysis: how to compute habitat-suitability maps without absence data? Ecology, 83(7), 2027-2036. DOI: 10.1890/0012-9658(2002)083[2027:ENFAHT]2.0.CO;2.

Hirzel, A.H., Helfer, V. \& Metral F. (2001). Assessing habitat-suitability models with a virtual species. Ecol. Model., 145, 111-121. DOI: 10.1016/ S0304-3800(01)00396-9.

Hori, J. (1966). Observations on Pochard and Tufted Duck breeding biology with particular reference to colonisation of a home range. Bird Study 13(4), 297-305. DOI: 10.1080/00063656609476133.

Hutchinson, G.E. (1957). Concluding remarks. Cold Spring Harbor Symp. Quant. Biol., 22, 415-457.

Hutchinson, G.E. (1965). The ecological theater and the evolutionary play. New Haven: Yale University Press.

Jensen, J.R. (2005). Introductory digital image processing: a remote sensing perspective. Upper Saddle River: Pearson Education.

Jin, S. \& Sader S.A. (2005). Comparison of time series tasseled cap wetness and the normalized difference moisture index in detecting forest disturbances. Remote Sens. Environ., 94, 364-372. DOI: 10.1016/j. rse.2004.10.012

Kaminski, R.M. \& Elmberg J. (2014). An introduction to habitat use and selection by waterfowl in the northern hemisphere. Wildfowl, Special Issue (4), 9-16.

Kear, J. (Ed.) (2005). Ducks, geese and swans volume 2: species accounts (Cairina to Mergus). Oxford: Oxford University Press.

Key, C.H. \& Benson N.C. (2006). Landscape assessment (LA): Sampling and analysis methods. In D.C. Lutes (Ed.), FIREMON: Fire Effects Monitoring and Inventory System. Gen. Tech. Rep. RMRS-GTR-164-CD. Fort Collins: U.S. Department of Agriculture, Forest Service, Rocky Mountain Research Station, LA1-LA51.

Kunah, O.M. \& Papka O.S. (2016). Ecogeographical determinants of the ecological niche of the common milkweed (Asclepias syriaca) on the basis of indices of remote sensing of land images. Visnyk of Dnipropetrovsk University. Biology, Ecology, 24(1), 78-86. DOI: 10.15421/011609.

Larson, M.A., Thompson III, F.R., Millspaugh, J.J., Dijak, W.D. \& Shifley S.R. (2004). Linking population viability, habitat suitability, and landscape simulation models for conservation planning. Ecol. Model., 180, 103118. DOI: $10.1016 /$ j.ecolmodel.2003.12.054.

Manyuk, Vol.V. \& Manyuk Vad.V. (2016). Geological and geomorphological studies for projecting the 'Orilskyi' national geopark. Dnipropetrovsk University Bulletin. Geology, Geography, 24(2), 70-91. DOI: 10.15421/111635. 
Nash, K.L., Allen, C.R., Angeler, D.G., Barichievy, C., Eason, T., Garmestani, A.S., Graham, N.A.J., Granholm, D., Knutson, M., Nelson, R.J., Nystrom, M., Stow, C.A. \& Sundstrom S.M. (2014). Discontinuities, cross-scale patterns, and the organization of ecosystems. Ecology, 95, 654-667. DOI: 10.1890/13-1315.1.

Navarro, G., Caballero, I., Silva, G., Parra, P.-C., Vázquez, Á. \& Caldeira R. (2017). Evaluation of forest fire on Madeira Island using Sentinel-2A MSI imagery. International Journal of Applied Earth Observation Geoinformation, 58, 97-106. DOI: 10.1016/j.jag.2017.02.003.

Oksanen, J., Blanchet, F.G., Kindt, R., Legendre, P., Minchin, P.R., O’Hara R.B., Simpson, G.L., Solymos, P., Stevens, M.H.H. \& Wagner H. (2017). Community Ecology Package. R package version 2.4-5. https://CRAN.Rproject.org/package $=$ vegan

Petkov, N. (2012). Habitat characteristics assessment of the wetlands with breeding Ferruginous Duck Aythya nyroca and Pochard A. ferina in Bulgaria. Acrocephalus, 32(150/151), 127-134. DOI: 10.2478/v10100-0110005-1.

Ponomarenko, O.L. (2017). On the method of the study of bird activity in forest stands (in Ukrainian). Vestn. Zool., 51, 68-72.

R Core Team (2015). A Language and Environment for Statistical Computing. http://www.R-project.org.

Ranjbar, A., Taabe, M., Mousavi, S.H. \& Khosroshahi M. (2018). Quantifying the vegetation health based on the resilience in an arid system. Ekológia (Bratislava), 37(1), 32-41. DOI: 10.2478/eko-2018-0004.

Resources Inventory Committee (1999). Inventory Methods for Waterfowl and Allied Species: Loons, Grebes, Swans, Geese, Ducks, American Coot and Sandhill Crane. Standards for Components of British Columbia's Biodiversity No. 18. Government of British Columbia, Resources Inventory Committee, Victoria, B.C., 1-11, 1-82.

Sentinel-2 (2012). Sentinel-2. ESA's Optical High-Resolution Mission for GMES Operational Services. (ESA SP-1322/2 March 2012). AG Noordwijk: ESA Communications.
Sims, D.A. \& Gamon J.A. (2002). Relationships between leaf pigment content and spectral reflectance across a wide range of species, leaf structures and developmental stages. Remote Sens. Environ., 81, 337-354. DOI 10.1016/S0034- 4257(02)00010-X

Tellería, J.L. (2016). Wildlife Habitat Requirements: Concepts and Research Approaches. In R. Mateo, B. Arroyo \& J.T. Garcia (Eds.), Current trends in wildlife research (pp. 79-96). Switzerland: Springer International Publishing. DOI: 10.1007/978-3-319-27912-1.

van Deventer, A.P., Ward, A.D., Gowda, P.H. \& Lyon J.G. (1997). Using thematic mapper data to identify contrasting soil plains and tillage practices. Photogrammetric Engineering \& Remote Sensing, 63, 87-93.

Wilson, E.H. \& Sader S.A. (2002). Detection of forest harvest type using multiple dates of Landsat TM imagery. Remote Sens. Environ., 80(3), 385-396. DOI: 10.1016/S0034-4257(01)00318-2.

$\mathrm{Xu}, \mathrm{H}$. (2006). Modification of normalised difference water index (NDWI) to enhance open water features in remotely sensed imagery. Int. J. Remote Sens., 27(14), 3025-3033. DOI: 10.1080/01431160600589179.

Yale Center for Earth Observation (2019). Landsat 8: Coastal Aerosol Band. https://surfaceheat.sites.yale.edu/sites/default/files/files/Coastal\%20 Aerosol\%20Band_1.pdf

Yorkina, N., Maslikova, K., Kunah, O. \& Zhukov O. (2018). Analysis of the spatial organization of Vallonia pulchella (Muller, 1774) ecological niche in Technosols (Nikopol manganese ore basin, Ukraine). Ecologica Montenegrina, 17, 29-45. DOI: 10.37828/em.2018.17.5.

Zimaroeva, A., Zhukov, A. \& Ponomarenko A. (2016). Determining spatial parameters of the ecological niche of Parus major (Passeriformes, Paridae) on the base of remote sensing data. Vestn. Zool., 50(3), 251-258. DOI: 10.1515/vzoo-2016-0029. 